\title{
Heat Unit Model for Predicting Bloom Dates in Rubus
}

\author{
Brent Black ${ }^{1}$ and James Frisby \\ Plants, Soils and Climate Department, Utah State University, 4820 Old Main \\ Hill, Logan, UT 84322-4820
}

Kimberly Lewers
USDA-ARS Genetic Improvement of Fruits and Vegetables Laboratory,
10300 Baltimore Ave., Beltsville, MD

Fumiomi Takeda

USDA-ARS Appalachian Fruit Research Station, 2217 Wiltshire Road, Kearneysville, $W V$

\section{Chad Finn}

USDA-ARS Horticultural Crops Research Laboratory, 3420 NW Orchard Ave., Corvallis, OR

Additional index words. blackberry, black raspberry, growing degree days, growing degree hours

\begin{abstract}
Navaho' and 'Apache' blackberry plants were maintained at 10, 15, 20, 25, 30, or $35^{\circ} \mathrm{C}$ in growth chambers to determine optimum temperature for budbreak and flowering (fewest days to flowering). In a separate experiment, bloom dates were observed for a collection of 117 Rubus genotypes over four seasons. Using these phenological data, predictive linear and curvilinear models were tested using a range of cardinal temperatures. The growth chamber experiment indicated optimum temperatures for bloom were $25.6^{\circ} \mathrm{C}$ for 'Apache' and $29.2^{\circ} \mathrm{C}$ for 'Navaho'. For the field observations, time to bloom was best defined by a linear model with base and optimum temperatures of 6 and $25^{\circ} \mathrm{C}$ and a curvilinear model defined by base and optimum temperatures of 4 and $27^{\circ} \mathrm{C}$, respectively. Based on the linear growing degree hour (GDH) model, heat units to bloom varied among cultivars in the collection from 9,200 GDH for 'Chickasaw' to 18,900 GDH for 'Merton Thornless'.
\end{abstract}

Some caneberry (Rubus L.) production regions experience dramatic seasonal variation in bloom date and fruit ripening time. Phenology and biology of flowering in both cultivated and wild raspberries (Rubus idaeus L.) and blackberries have been studied under diverse environmental conditions in Scotland (Robertson, 1957) and throughout the United States, including in Maryland (Waldo, 1933), Missouri (Warmund and George, 1990; Warmund and Krumme, 2005), Oregon (Takeda et al., 2002; Waldo, 1933), and

Received for publication 20 June 2008. Accepted for publication 19 Aug. 2008.

Funding for this work was provided by a grant from the North American Raspberry and Blackberry Association, by the USDA-ARS, and by the Utah Agriculture Experiment Station-Utah State University (Journal paper no. 7981).

We acknowledge the technical assistance of Ingrid Fordham, Philip Edmonds, John Enns, Kate Rappaport, Sarah Nourse Styan, Sam Garrett, Mchez Axum, and Ann Hummell.

Mention of trade names or commercial products in this article is solely for the purpose of providing specific information and does not imply recommendation or endorsement by the Utah Agriculture Experiment Station or U.S. Department of Agriculture.

${ }^{1}$ To whom reprint requests should be addressed; e-mail brent.black@usu.edu were not useful in predicting bloom date. However, no details were provided as to how these accumulated heat units were calculated. In eastern West Virginia, flowering in semierect 'Black Satin', 'Dirksen Thornless', and 'Hull Thornless' blackberries occurred over a 5 -week period and fruits with bloom dates of 7,14 , and 21 June needed 50, 55, and $61 \mathrm{~d}$ to reach maturity (Takeda, 1987). It appeared that bloom date affected the onset of fruit development as well as maturation rate, but that study did not use temperature recordings to account for seasonal variations in the onset of bloom in the spring and the fruit-ripening period in summer.

Models that reliably predict bloom and fruit ripening are useful in understanding the environmental constraints on crop development, which in turn is useful in matching genotypes to their environment for optimum cropping. An understanding of how environmental conditions affect plant development has also been used in an attempt to predict the potential impacts of global climate change (Hanninen, 1995). Furthermore, increased interest in producing blackberries in protected cultivation (Strik et al., 2007) requires a better understanding of the relationship between temperature and crop development. This is particularly important in managing greenhouses and high tunnels designed to advance fruiting (Heidenreich et al., 2008).

For processes that are primarily temperature-driven, a measure of heat unit accumulation accounts for seasonal differences in development time. The basic concept in heat unit accumulation is that growth occurs when temperatures are above some minimum (base temperature) and that growth rate increases with temperature. Further refinements provide for optimum and critical temperatures (Richardson et al., 1975). The optimum temperature is the point at which there is no longer a continued increase in growth rate (plateau), whereas the critical temperature is the maximum temperature at which growth will continue. Historically, temperature data were often limited to daily maximum and minimum, in which growing degree day accumulation was based on averaging the daily maximum and minimum subtracting the base temperature and summing this value for each day (Arnold, 1960). A refinement on this method is according to Baskerville and Emin (1969) in which a sine curve is fitted to daily maximum and minimum temperatures to approximate diurnal fluctuations and thereby estimates the amount of time each day when temperatures exceed the base temperature for growth. With improvements in automated weather monitoring, it is now practical to calculate heat unit accumulation on an hourly basis and sum growing degree hours (GDH), eliminating the need to mathematically approximate diurnal fluctuations.

A linear model for accumulated heat units (Anderson and Seeley, 1992) can be defined by a basal, optimum, and critical temperature (Fig. 1). A further refinement of this model is the use of an asymmetric curvilinear relationship (ASYMCUR) between temperature and 


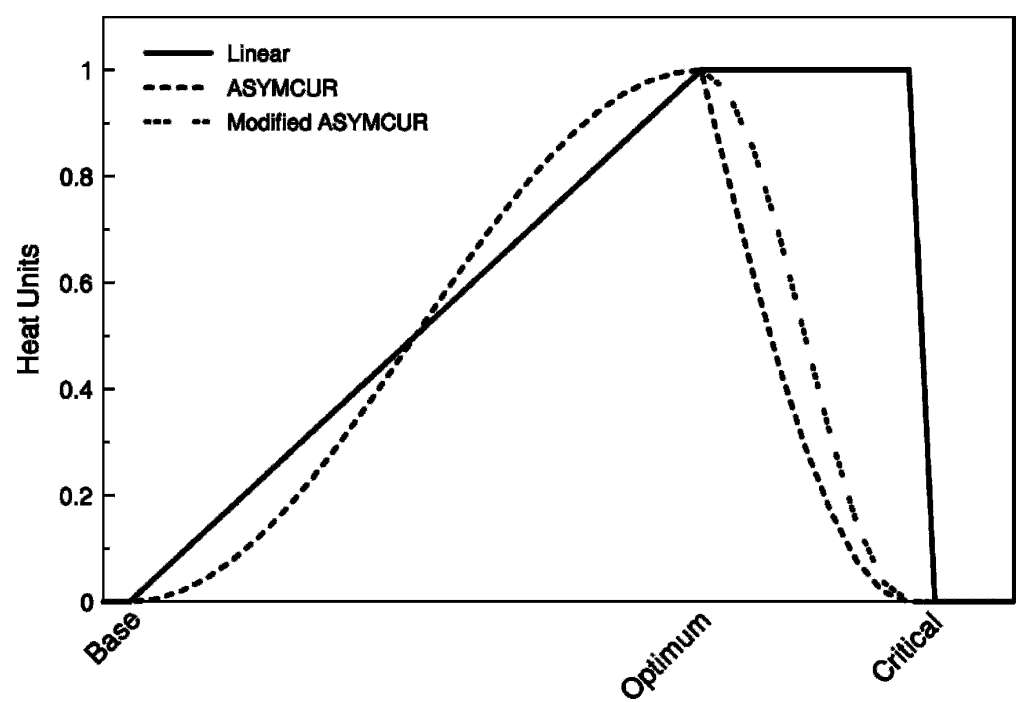

Fig. 1. Relative heat unit accumulation for the linear, ASYMCUR, and modified ASYMCUR models. ASYMCUR is according to Anderson et al. (1986). ASYMCUR modifications are by Roundy and Frisby (unpublished data). ASYMCUR = asymmetric curvilinear relationship.

growth (Anderson et al., 1986). The purpose of this work was to determine heat requirements for bloom in Rubus, primarily blackberry, under both controlled environment and field conditions.

\section{Materials and Methods}

Growth chamber study. Primocanes of 5and 6-year-old 'Navaho' and 'Apache' blackberry plants were dug from the field at the USDA-ARS Appalachian Fruit Research Station in Kearneysville, WV, in early November of 2003 and 2004 and potted into 11-L nursery pots containing Fafard Mix No. 4 (Conrad Fafard, Inc., Agawam, MA). These plants were combined with tissue culture plants of 'Navaho' that had been established in 11-L pots in 2003. Plants were assigned to one of five blocks according to origin, transplant date, and size and moved to cold storage $\left(6{ }^{\circ} \mathrm{C}\right)$ on 3 Dec. 2004. On 28 Dec. 2004, five plants from each block were removed from cold storage and pruned to a single floricane that was cut back to $0.9 \mathrm{~m}$ height when necessary. Pruned plants were then placed in one of five randomly assigned growth chambers (Conviron E15, Winnipeg, Canada) programmed at $10,15,20,25,30$, or 35 ${ }^{\circ} \mathrm{C}$ constant temperature and a $16-\mathrm{h}$ photoperiod. Plants were observed at least twice weekly for $65 \mathrm{~d}$ to determine dates of budbreak and of first open flower. On 3 Mar., these plants were removed from the chambers and the experiment repeated with a second set of plants that had been maintained in cold storage at $5{ }^{\circ} \mathrm{C}$. Air temperature near the base of the plant canopy and soil temperatures at $8-$ to $10-\mathrm{cm}$ depth were recorded within the growth chamber environments using thermocouples attached to a data logger (CR-7; Campbell Scientific, Logan, UT). Data were analyzed in the PROC GLM procedure of SAS (SAS Institute, Cary, NC) using orthogonal contrast coefficients for uniformly spaced treatments to determine the relationship between temperature and time to flowering.

Field study. A collection of 125 blackberry, red raspberry-blackberry hybrid, and black raspberry ( $R$. occidentalis L.) genotypes, primarily of eastern North America origin, was established in 2000 at the Henry A. Wallace Beltsville Agricultural Research Center, Beltsville, MD. The majority of the numbered selections were from the USDA-ARS breeding program at Beltsville, MD. A lesser number were from the breeding programs at the University of Arkansas, North Carolina State University, and the University of Maryland. Two replicate plots were established for 53 of the genotypes with four plants per replicate. For the remaining genotypes, there was insufficient plant numbers to establish replicate plots, and a single plot was established with one to four plants per plot. Canes were trained to a vertical trellis, and a 1-m weed-free strip was maintained under the plants with the use of a woven plastic weed barrier. Supplemental irrigation was supplied through a drip line placed within each row. The soil at the site was a Croom-Downer complex consisting of a deep, well-drained gravelly sandy loam with $3 \%$ to $8 \%$ slope.

Observations of the date when the first flower opened and the first fruit was fully colored were made twice weekly during the 2002 to 2005 seasons. Weather data, including hourly temperature and photosynthetic photon flux, were collected using an automated weather station located within $160 \mathrm{~m}$ of all points of the planting. The program WinTree (Rojas-Martinez et al., 1999) was used to calculate GDH based on linear and curvilinear heat unit models using a range of cardinal temperatures. The curvilinear models included ASYMCUR (Anderson et al., 1986) and a modified ASYMCUR (Roundy and Frisby, unpublished data). The difference between the two ASYMCUR models is in how temperatures between optimum and maximum are treated. A comparison of these models is shown in Figure 1. Each model was optimized for cardinal temperatures and compared by multiple regression analysis to maximize the coefficient of regression.

\section{Results and Discussion}

Growth chamber study. All of the plants held at $10^{\circ} \mathrm{C}$ flowered within $76 \mathrm{~d}$, indicating a base temperature below $10{ }^{\circ} \mathrm{C}$. All of the 'Apache' plants and approximately half of the 'Navaho' plants held at $35^{\circ} \mathrm{C}$ either died or failed to flower after $76 \mathrm{~d}$. For the second run of the experiment, the plants flowered $\approx 5$ d later than for the first run, but the trend across temperatures was identical and data for the two runs were averaged. The optimum temperature to achieve the shortest time to flowering was between 25 and $30{ }^{\circ} \mathrm{C}$ for both cultivars. Fitted curves predicted that the temperature optimum was $25.6^{\circ} \mathrm{C}$ for 'Apache' and $29.2^{\circ} \mathrm{C}$ for 'Navaho' (Fig. 2).

Field study. Date of first bloom varied from season to season. Averaged over all genotypes, first bloom ranged from 1 May in 2002 to 17 May in 2005 with average first bloom in 2003 and 2004 occurring on 16 May and 10 May, respectively. Some plant loss occurred over the course of the experiment and diseased or dying plants were excluded from the calculations with 117 of the original 125 genotypes included in the final calculations.

A range of base and optimum temperatures were compared in each model by selecting those that provided the maximum regression coefficient. For the field study, there were relatively few days before bloom in which temperatures were above $30{ }^{\circ} \mathrm{C}$, making it difficult to define a critical temperature for either the linear or curvilinear model. The growth chamber study indicated critical temperatures for blackberry near $35^{\circ} \mathrm{C}$. However, it should be noted that the potted plants in the growth chamber study also experienced elevated soil temperatures that likely would not be achieved under field conditions. Although it was previously shown that soil temperature had no effect on time to anthesis (Hammond and Seeley, 1978), the soil temperatures experienced by a potted plant held in a growth chamber at a constant $35{ }^{\circ} \mathrm{C}$ would be dramatically higher than in the field. For calculating the models, $37^{\circ} \mathrm{C}$ was used as a critical temperature in all models.

The best fit models were a linear model defined by base and optimum temperatures of 6 and $25{ }^{\circ} \mathrm{C}$ and a modified ASYMCUR model defined by base and optimum temperatures of 4 and $27^{\circ} \mathrm{C}$, respectively $\left(R^{2}>0.85\right.$, Table 1). By contrast, calendar date showed an $R^{2}=0.602$. Multiple regression analysis indicated that the linear and curvilinear models adequately accounted for seasonal variations in bloom date when cardinal temperatures were optimized for each model. The best fit linear and curvilinear models produced different optimum and critical temperatures that can be explained by the 


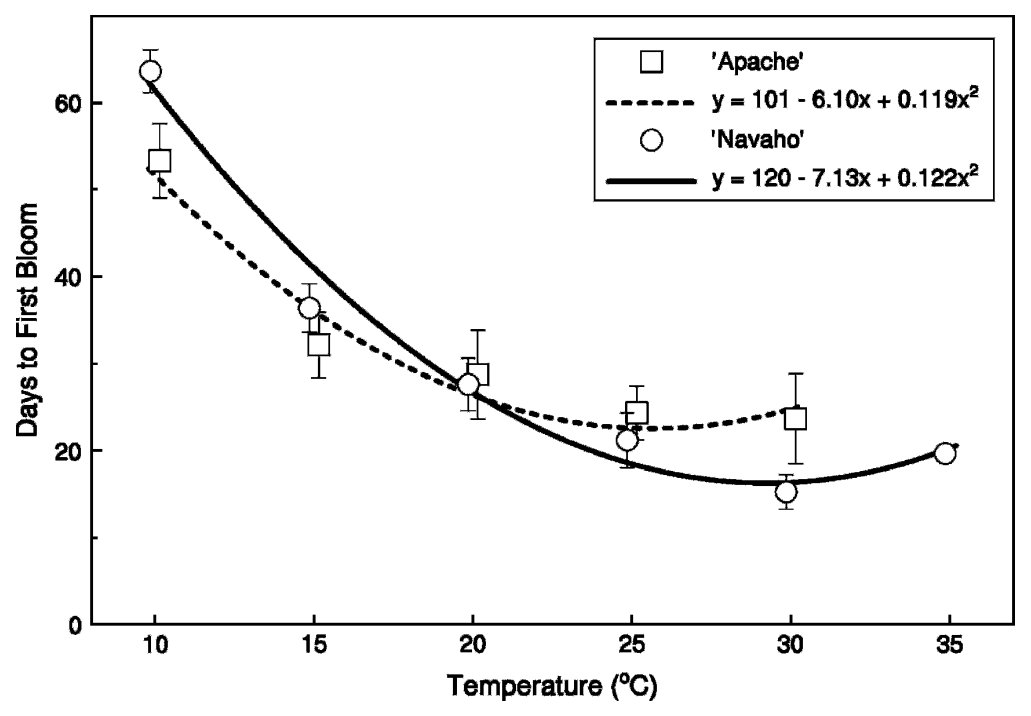

Fig. 2. Time to flowering of 'Navaho' and 'Apache' blackberry at five temperatures. Values are the means \pm SE of five replicate plants and two repeat experiments.

Table 1. Optimized cardinal temperatures for linear, ASYMCUR, and modified ASYMCUR models for predicting date of anthesis in a collection of Rubus selections and cultivars.

\begin{tabular}{lccc}
\hline & \multicolumn{3}{c}{ Temperature $\left({ }^{\circ} \mathrm{C}\right)$} \\
\cline { 2 - 3 } Model type & Base & Optimized & $R^{2}$ \\
\hline Linear & 6 & 25 & 0.8515 \\
ASYMCUR & 4 & 28 & 0.8508 \\
Modified ASYMCUR & 4 & 27 & 0.8514 \\
\hline
\end{tabular}

inherent differences in these models. Base temperature was higher in the linear model than in the two curvilinear models, which can be explained by the characteristic lag in a sigmoid curve (Fig. 1). Likewise, the optimum temperature differed among the models in relation to how each model treated temperatures between optimum and critical.
Heat requirements to bloom can also be influenced by the amount of dormant chilling that a plant receives. Inadequate chilling may delay response to warm temperatures and result in asynchronous budbreak (Seeley, 1996). Chilling in excess of plant requirements has been shown to reduce the amount of heat necessary for budbreak in several tree fruit species (Couvillon and Erez, 1985). Optimum chilling for 'Navaho' is reported to be between 800 and $900 \mathrm{~h}$ at $3{ }^{\circ} \mathrm{C}$ (Drake and Clark, 2000). Warmund and Krumme (2005) reported that 'Apache' had a relatively longer chilling requirement than 'Navaho' and several other Arkansas cultivars (although the exact number of chill hours was not given and a different model was used). Some Arkansas blackberry cultivars typically have chilling requirements less than $700 \mathrm{~h}$ and may be as little as $200 \mathrm{~h}$

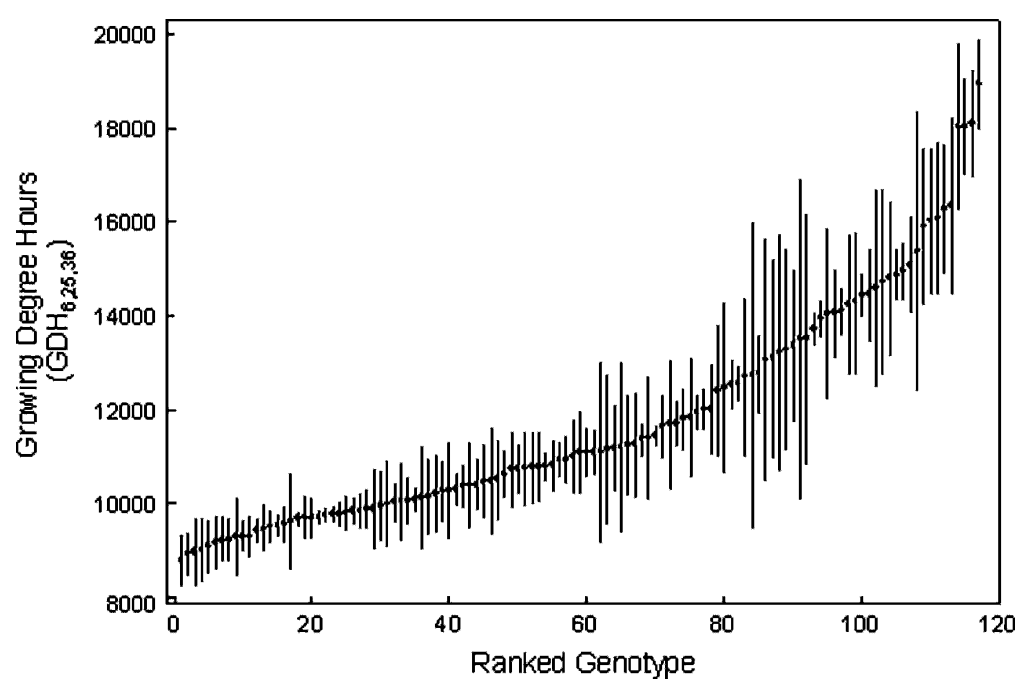

Fig. 3. Heat units $\left(\mathrm{GDH}_{6,25,36}\right)$ to flowering in 117 Rubus genotypes. Vertical lines represent SD as an indicator of seasonal variation. Genotypes are plotted by ranked GDH to flowering. The ranks corresponding to each genotype are shown in Tables 2 through 6 . Heat units are calculated using a linear model with 6,25 , and $36^{\circ} \mathrm{C}$ as base, optimum, and maximum temperatures, respectively. GDH $=$ growing degree hours.
Table 2. Mean heat units to first flowering for Rubus cultivars and selections from the USDAARS breeding programs at Beltsville, MD, and Carbondale, IL.

\begin{tabular}{|c|c|c|c|}
\hline \multirow[b]{2}{*}{ Cultivar/selection } & \multicolumn{2}{|c|}{$\mathrm{GDH}_{(6,25,36)}$} & \multirow[b]{2}{*}{ Replication } \\
\hline & Mean $^{z}$ & $\operatorname{Rank}^{\mathrm{y}}$ & \\
\hline Black Satin & 11,100 & 60 & Yes \\
\hline Chester Thornless & 14,430 & 99 & Yes \\
\hline Hull Thornless & 9,980 & 31 & Yes \\
\hline Smoothstem & 18,090 & 115 & Yes \\
\hline Thornfree & 16,280 & 111 & Yes \\
\hline Triple Crown & 14,050 & 95 & Yes \\
\hline B2-4 & 10,360 & 42 & No (1) \\
\hline B5-4 & 10,390 & 44 & No (3) \\
\hline US1637 & 8,780 & 1 & No (4) \\
\hline US1670 & 9,750 & 22 & No (1) \\
\hline US1688 & 15,080 & 106 & No (1) \\
\hline US1705 & 12,690 & 82 & No (3) \\
\hline US1713 & 10,470 & 46 & No (3) \\
\hline US1721 & 11,930 & 75 & No (4) \\
\hline US1729 & 15,370 & 107 & No (2) \\
\hline US1730 & 12,530 & 80 & No (4) \\
\hline US1732 & 11,080 & 59 & No (2) \\
\hline US1733 & 12,390 & 78 & No (1) \\
\hline US1736 & 10,270 & 40 & No (1) \\
\hline US1749 & 11,440 & 69 & No (2) \\
\hline US1754 & 14,950 & 105 & No (3) \\
\hline US1762 & 13,490 & 90 & No (3) \\
\hline US1765 & 21,710 & 117 & No (4) \\
\hline US1766 & 11,700 & 72 & No (1) \\
\hline US1767 & 10,610 & 48 & No (4) \\
\hline US1769 & 12,730 & 83 & No (1) \\
\hline US1773 & 10,780 & 53 & No (1) \\
\hline US1774 & 12,000 & 77 & No (1) \\
\hline US1777 & 13,510 & 91 & No (2) \\
\hline US1779 & 10,740 & 51 & No (1) \\
\hline US1780 & 9,830 & 27 & No (1) \\
\hline US1794 & 11,800 & 73 & No (3) \\
\hline US1797 & 9,400 & 12 & Yes \\
\hline US1798 & 10,750 & 52 & No (1) \\
\hline US1799 & 10,140 & 37 & No (1) \\
\hline US1811 & 13,710 & 92 & No (1) \\
\hline US1818 & 9,760 & 23 & No (1) \\
\hline US1821 & 10,200 & 38 & Yes \\
\hline US1824 & 16,060 & 110 & No (1) \\
\hline US1839 & 13,340 & 89 & No (1) \\
\hline US1842 & 12,760 & 84 & No (2) \\
\hline US1844 & 15,900 & 108 & No (1) \\
\hline US1846 & 14,040 & 94 & No (1) \\
\hline US1849 & 9,280 & 10 & No (1) \\
\hline US1861 & 12,460 & 79 & No (2) \\
\hline US1865 & 14,590 & 101 & No (1) \\
\hline US1866 & 14,440 & 100 & No (3) \\
\hline US1872 & 14,290 & 98 & No (1) \\
\hline US1873 & 14,860 & 104 & No (1) \\
\hline US1874 & 13,940 & 93 & No (1) \\
\hline US1875 & 14,080 & 96 & No (1) \\
\hline US1876 & 10,070 & 35 & No (2) \\
\hline US1877 & 14,720 & 102 & No (1) \\
\hline US1878 & 18,030 & 114 & No (1) \\
\hline US1880 & 11,070 & 58 & No (1) \\
\hline US1882 & 14,240 & 97 & No (3) \\
\hline US1888 & 13,080 & 86 & No (2) \\
\hline US1962 & 13,270 & 88 & No (1) \\
\hline Black raspberries & & & \\
\hline US1775 & 10,460 & 45 & No (1) \\
\hline US1782 & 11,390 & 68 & No (1) \\
\hline US1789 & 9,290 & 11 & No (1) \\
\hline US1795 & 13,040 & 85 & No (1) \\
\hline US1803 & 18,020 & 113 & No (1) \\
\hline US1804 & 9,450 & 13 & No (2) \\
\hline US1805 & 16,350 & 112 & No (1) \\
\hline
\end{tabular}

${ }^{2}$ Heat units calculated as growing degree hours (GDH) using a linear model with 6,25 , and $36{ }^{\circ} \mathrm{C}$ as base, optimum, and maximum temperatures, respectively.

${ }^{y}$ Relative earliness ranked for each genotype, in which the lowest numbers represent the fewest heat units to bloom.

${ }^{x}$ There were not sufficient numbers to establish replicated plots for some selections, and a single plot was established for each. The number of plants in nonreplicated plots is shown in parentheses. 
(Drake and Clark, 2000; Yazzetti and Clark, 2001). Two replicate runs of the growth chamber experiment were carried out over the course of one winter. Plants used for the first run received $600 \mathrm{~h}$ of chilling in cold storage in addition to any chilling received in the field before transplanting. Plants used in the second run received $1400 \mathrm{~h}$ more chilling than those in the first run. Chilling temper-

Table 3. Heat units to first flowering for Rubus cultivars and selections from the breeding program at the University of Arkansas.

\begin{tabular}{lrrc}
\hline Cultivar & \multicolumn{2}{c}{$\mathrm{GDH}_{(6,25,36)}$} & \\
\cline { 2 - 3 } selection & Mean $^{\mathrm{z}}$ & Rank $^{\mathrm{y}}$ & Replication \\
\hline Apache & 10,040 & 33 & Yes \\
Arapaho & 10,500 & 47 & Yes \\
Cherokee & 10,260 & 39 & Yes \\
Cheyenne & 9,670 & 18 & Yes \\
Chickasaw & 9,200 & 7 & Yes \\
Navaho & 10,800 & 54 & Yes \\
Ouachita & 11,140 & 62 & Yes \\
Shawnee & 9,620 & 17 & Yes \\
A 1631 & 9,500 & 14 & Yes \\
A 1689T & 11,170 & 63 & Yes \\
A 1713 & 9,700 & 21 & Yes \\
A 1811 & 9,520 & 15 & Yes \\
A 1817T & 9,760 & 24 & Yes \\
A 1818T & 9,680 & 19 & Yes \\
A 1844 & 9,950 & 30 & Yes \\
A 1854 & 9,070 & 5 & Yes \\
A 1857T & 9,830 & 26 & Yes \\
A 1942T & 10,930 & 55 & Yes \\
A 1959T & 11,230 & 65 & No (3) \\
A 1963T & 13,220 & 87 & Yes \\
A 2005T & 9,220 & 8 & Yes \\
A 2049T & 9,270 & 9 & Yes \\
\hline
\end{tabular}

${ }^{2}$ Heat units calculated as growing degree hours (GDH) using a linear model with 6,25 , and $36{ }^{\circ} \mathrm{C}$ as base, optimum, and maximum temperatures, respectively.

${ }^{\mathrm{y}}$ Relative earliness ranked for each genotype, in which the lowest numbers represent the fewest heat units to bloom.

${ }^{\mathrm{x}}$ Where only one plot of a genotype existed, the number of plants in the plot is shown in parentheses.

Table 4. Heat units to first flowering for Rubus selections from the breeding program at the North Carolina State University.

\begin{tabular}{lrrl}
\hline Cultivar/ & \multicolumn{2}{c}{$\mathrm{GDH}_{(6,25,36)}$} & \\
\cline { 2 - 3 } selection & $\mathrm{Mean}^{\mathrm{z}}$ & Rank $^{\mathrm{y}}$ & Replication $^{\mathrm{x}}$ \\
\hline NC 95-2-1 & 11,630 & 70 & No (4) \\
NC 378 & 11,240 & 66 & No (4) \\
NC 383 & 8,920 & 2 & Yes \\
NC 385 & 12,000 & 76 & Yes \\
NC 387 & 11,000 & 57 & Yes \\
NC 388 & 10,120 & 36 & No (4) \\
NC 392 & 11,370 & 67 & Yes \\
NC 395 & 10,930 & 56 & Yes \\
NC 408 & 9,010 & 4 & No (2) \\
NC 415 & 8,950 & 3 & No (3) \\
NC 430 & 10,380 & 43 & Yes \\
\hline
\end{tabular}

${ }^{\mathrm{z}}$ Heat units calculated as growing degree hours (GDH) using a linear model with 6,25 , and $36{ }^{\circ} \mathrm{C}$ as base, optimum, and maximum temperatures, respectively.

${ }^{y}$ Relative earliness ranked for each genotype, in which the lowest numbers represent the fewest heat units to bloom.

${ }^{x}$ Where only one plot of a genotype existed, the number of plants in the plot is shown in parentheses.
Table 5. Heat units to first flowering and fruit ripening time for Rubus cultivars and selections from the breeding program at the University of Maryland.

\begin{tabular}{lrcc}
\hline Cultivar/ & \multicolumn{2}{c}{$\mathrm{GDH}_{(6,25,36)}$} & \\
\cline { 2 - 3 } selection & $\mathrm{Mean}^{\mathrm{z}}$ & Rank $^{\mathrm{y}}$ & Replication \\
\hline Chesapeake & 10,720 & 50 & Yes \\
Raven & 9,560 & 16 & Yes \\
OAL-W3 & 11,680 & 71 & Yes \\
OAL-W6 & 11,830 & 74 & No (4) \\
QCU-1 & 9,870 & 28 & Yes \\
QDB-1 & 10,020 & 32 & Yes \\
QDB-2 & 11,190 & 64 & No (3) \\
QDB-b1 & 10,300 & 41 & Yes \\
QDE-1 & 9,880 & 29 & Yes \\
QDE-2 & 9,160 & 6 & Yes \\
QDE-3 & 11,100 & 61 & Yes \\
QEZ-1 & 14,790 & 103 & Yes \\
\hline
\end{tabular}

${ }^{\mathrm{z}}$ Heat units calculated as growing degree hours (GDH) using a linear model with 6,25 , and $36{ }^{\circ} \mathrm{C}$ as base, optimum, and maximum temperatures, respectively.

${ }^{y}$ Relative earliness ranked for each genotype, in which the lowest numbers represent the fewest heat units to bloom.

${ }^{x}$ Where only one plot of a genotype existed, the number of plants in the plot is shown in parentheses.

atures in excess of plant requirements did not significantly reduce heat unit requirements, but rather heat unit requirements were slightly greater in the second run.

The best heat unit model for the genotypes included in this study did not account for all variation in bloom. Aside from temperature and chilling, other factors that may influence budbreak and anthesis include plant age and vigor, bud position on the cane (Takeda, 1987; Takeda et al., 2002), cold injury, and genetics. Considering genetic variation, it would likely be possible to determine specific cardinal temperatures for each genotype. However, a more applicable model would be one that reasonably predicts bloom across a number of genotypes.

Genotypic differences. The heat units required to promote flowering varied dramatically by genotype with more than a twofold difference in GDH to bloom among genotypes, indicating significant genetic variation (Fig. 3). Among cultivars in the collection, GDH to bloom varied from 9,200 GDH for 'Chickasaw' to 18,900 GDH for 'Merton

Table 6. Heat units to first flowering and fruit ripening time for blackberry cultivars from various sources.

\begin{tabular}{lcccl}
\hline \multirow{2}{*}{ Cultivar/selection } & \multicolumn{2}{c}{$\mathrm{GDH}_{(6,25,36)}$} & & \\
\cline { 2 - 5 } & $\mathrm{Mean}^{\mathrm{z}}$ & Rank $^{\mathrm{y}}$ & Replication & \multicolumn{1}{c}{ Source } \\
\hline Aurora & 9,690 & 20 & Yes & USDA-Oregon \\
Bailey & 10,720 & 49 & Yes & New York \\
Ebano & 12,550 & 81 & Yes & Brazil \\
Illini Hardy & 10,050 & 34 & Yes & U. Illinois \\
Lucretia & 9,800 & 25 & No (3) & West Virginia \\
Merton Thornless & 18,940 & 116 & Yes & UK John Innes Inst. \\
Perron's Black & 16,010 & 109 & Yes & Quebec \\
\hline
\end{tabular}

${ }^{2}$ Heat units calculated as growing degree hours (GDH) using a linear model with 6,25 , and $36{ }^{\circ} \mathrm{C}$ as base, optimum, and maximum temperatures, respectively.

${ }^{y}$ Relative earliness ranked for each genotype, in which the lowest numbers represent the fewest heat units to bloom.

${ }^{x}$ Where only one plot of a genotype existed, the number of plants in the plot is shown in parentheses. 
integral added to the model, the predictive value was increased. However, for the seasons observed, these models were not significantly better than simply counting calendar days (data not shown). This suggests that influences of environmental conditions on fruit development are clearly more complex than a simple temperature relationship. A more refined model that integrates temperature, light, and photosynthesis limitations may need to be developed to account for seasonal differences in fruit ripening time. Our findings directly contradict those of Jennings (1979) who reported that their undefined heat units predicted fruit development (time from flowering to ripe fruit) but did not work well for predicting bloom date. This contradiction may be the result of the increased number of genotypes in the present study and improved methods for determining heat accumulation, including the use of optimal and critical temperatures and summing heat units on an hourly basis.

\section{Literature Cited}

Anderson, J.L., E.A. Richardson, and C.D. Kesner. 1986. Validation of chill unit and flower bud phenology models for 'Montmorency' sour cherry. Acta Hort. 184:71-75.

Anderson, J.L. and S.D. Seeley. 1992. Modelling strategy in pomology: Development of the Utah models. Acta Hort. 313:297-306.

Arnold, C.Y. 1960. Maximum-minimum temperatures as a basis for computing heat units. Proc. Amer. Soc. Hort. Sci. 76:682-692.

Baskerville, G.L. and P. Emin. 1969. Rapid estimation of heat accumulation from maximum and minimum temperatures. Ecology 50:514-517.
Clark, J.R., E.T. Stafne, K. Hall, and C.E. Finn. 2007. Blackberry breeding and genetics. Plant Breed. Rev. 29:19-144.

Couvillon, G.A. and A. Erez. 1985. Influence of prolonged exposure to chilling temperatures on bud break and heat requirement for bloom of several fruit species. J. Amer. Soc. Hort. Sci. 110:47-50.

Drake, C.A. and J.R. Clark. 2000. Determination of the chilling requirement of Arkansas thornless blackberry cultivars. Student Journal. Dale Bumpers College of Agr. Food, and Life Sci. $1: 30-32$.

Hammond, M.W. and S.D. Seeley. 1978. Spring bud development of Malus and Prunus species in relation to soil temperature. J. Amer. Soc. Hort. Sci. 103:655-657.

Hanninen, H. 1995. Effects of climatic change on trees from cool temperature regions: An ecophysiological approach to modeling of bud burst phenology. Canadian Journal of Botany-Revue Canadienne de Botanique. 73:183-199.

Heidenreich, C., M.P. Pritts, M.J. Kelly, and K. Demchak. 2008. High tunnel raspberries and blackberries. Cornell University, Department of Horticulture. Publication No. 47:31.

Hoover, E., J. Luby, D. Bedford, M.P. Pritts, E. Hanson, A. Dale, and H. Daubeny. 1989. Temperature influence on harvest date and cane development of primocane-fruiting raspberries. Acta Hort. 262:297-303.

Jennings, D.L. 1979. Genotype-environment relationships for ripening time in blackberries and prospects for breeding an early ripening cultivar for Scotland. Euphytica 28:747-750.

Moore, J.N. and J.D. Caldwell. 1985. Rubus. In: Halevy, A.H. (ed.) CRC handbook of flowering. Vol. 4. CRC Press, Boca Raton, FL.

Richardson, E.A., S.D. Seeley, D.R. Walker, J.L Anderson, and G.L. Ashcroft. 1975. Phenoclimatography of spring peach bud development. HortScience 10:236-237.
Robertson, M. 1957. Further investigation of flower-bud development in the genus Rubus. J. Hort. Sci. 32:265-273.

Rojas-Martinez, R., S.D. Seeley, J.L. Anderson, J.W. Frisby, and J.I. d. Real-Laborde. 1999. WinTree: A computer program for calculating chill and anthesis units used in modeling fruit tree phenology. Acta Hort. 499:245-250.

Seeley, S.D. 1996. Modeling climatic regulation of bud dormancy, p. 361-376. In: Lang, G.A. (ed.). Plant dormancy: Physiology, biochemistry, and molecular biology. CAB Intl., Wallingford, Oxon, UK.

Strik, B.C., J.R. Clark, C.E. Finn, and M.P. Bañados. 2007. Worldwide blackberry production. HortTechnology 17:205-213.

Takeda, F. 1987. Some factors associated with fruit maturity range in cultivars of the semi-erect, tetraploid thornless blackberry. HortScience 22:405-408.

Takeda, F., B.C. Strik, D. Peacock, and J.R. Clark. 2002. Patterns of floral bud development in canes of erect and trailing blackberries. J. Amer. Soc. Hort. Sci. 128:3-7.

Takeda, F. and M.E. Wisniewski. 1989. Organogenesis and patterns of floral bud development in two eastern thornless blackberry cultivars. J. Amer. Soc. Hort. Sci. 114:528-531.

Waldo, G.F. 1933. Fruit bud formation in brambles. Proc. Amer. Soc. Hort. Sci. 30:263-267.

Warmund, M.R. and M.F. George. 1990. Freezing survival and supercooling in primary and secondary buds of Rubus spp. Can. J. Plant Sci. 70:893-904.

Warmund, M.R. and J. Krumme. 2005. A chilling model to estimate rest completion of erect blackberries. HortScience 40:1259-1262.

Yazzetti, D. and J.R. Clark. 2001. Evaluation of chilling requirements for six Arkansas blackberry cultivars utilizing stem cuttings. Discovery: Student Journal Dale Bumpers College of Agr. Food, and Life Sci. 2:57-62. 